and leave a vacuum between the two, and not only would the inspiratory muscles be incompetent to do this, bat no force which can be imagined, not even one equal to $15,000,000$ pounds or 15,000,000 tons to the square inch of chest surface, wonld be competent to do this, for in the process of expansion the thoracic walls or the lungs would rupture long before such a vacuum could be brought about. As a matter of fact, the inspiratory muscles are competent to expand the chest to its potential maximum, as may be observed in advanced cases of hypertrophous emphysema.

May I, Sir, in concluding this long letter venture to express the hope that this time the energy expended may not be entirely lost on Sir James Barr. Certain it is that I shall be more than content if it proves as profitable to him or to others as are the respiratory struggles of the unfortunate asthmatic profitable to the latter, convinced as I am that those struggles, blind and purposeless as they may appear to the casual observer, are yet wisely directed towards a useful end, and that but for them no patient could battle through a severe asthmatic paroxysm. Nature is not always such a fool as some seem to think.

I am, Sir, yours faithfully,

Wimpole-street, Feb. 2nd, 1908. HaRry CAMPBell.

\section{THE CAUSE OF THE PREVALENCE OF ADENOIDS.}

To the Elitor of THE LANCET.

SIR,-I am glad Dr. J. Sim Wallace does not " put any importance on" his figures, for even more startling deductions might be made from them. As his five shutwindow families have 26 children and his five open-window families but 19 he might have argued that closed windows at night increased the number of children born, and closed windows might be recommended to the President of the United States as a cure for race-suicide! But joking apart, I do not think Dr. Wallace will find that his theory is supported by facts. I think the explanation of his numbers, if one is needed, is that adenoid families see a lot of the doctor and where the doctor rules the windows are open at night. If adenoids are on the increase it cannot be due to open windows, for windows that really shut are of quite recent introduction. The old leaded glass always leaked and it is only since it was superseded that the bedcurtains and night-caps of our parents have been done away with.

I am, Sir, yours faithfully.

$$
\text { O. Clayton Jones, M.B. Oxon. }
$$

Silverton, Exeter, Jan. 29th, 1908.

\section{THE RESPONSIBILITY FOR THE AN ASTHETIC. \\ To the Editor of THE LANCET.}

SIR, - It is to be hoped that Dr. Dudley W. Buxton's paper in THE LANCET of Jan. 18th, p. 151, and your leading article thereon have been very carefully read not only by surgeons and anæsthetists but also by general practitioners. It happens far too commonly that a practitioner who calls in a surgeon to perform an operation-whatever the nature of this may be-suggests, and even requests, that he or his partner or assistant may give the anæsthetic, although there may be no adequate reason for not engaging a skilled ansesthetist. When such a request is made to a surgeon it is, of course, not easy for him to refuse, although he may have grave misgivings as to the result of his consent and although be may be well aware that the operator who permits a person of small experience to give an anæsthetic accepts a very serious responsibility.

I have no doubt such an arrangement is usually suggested in all good faith, for the majority of practitioners whom I have met do not seem to realise that for the proper conduction of a large proportion of the operations done at the present time special skill and experience are as needful in the anæsthetist as in the surgeon, and that the average practitioner cannot expect to be any more capable of replacing the one than the other. It is necessary not only to know the kind of anæsthetic best suited to the patient and to the operation but also to be well acquainted with the surgical procedure in order that pitfalls may be avoided. This is especially the case with operations on internal organs and above all with those (even "trivial" ones) on the upper airpassages, where safety and success can only be attained by a knowledge of the operator's methods and a perfect coopperation between him and the anæsthetist. So many instances have come to $m y$ knowledge where want of special experience in a self-constituted anæsthetist has led to inconvenience and even disaster that I venture to trouble you with this letter.

I am, Sir, yours faithfully,

Jan. 25th, 1908.

F.R.C.S.

\section{THE PRESENT PROSPECTS OF THE MEDICAL PROFESSION. \\ To the Editor of THE LANCET.}

SIR. - The remarks of "Inspector-General" in your issue of Jan. 25th are worthy of the very greatest consideration, and call for more than ordinary passing comments in your correspondence columns. Indeed, a change of government in the whole attitude and conduct of modern professional manners is sadly needed. Everything is moving too quickly nowadays and this is not foreign to ourselves. There is a rush, a congestion, and a competition in our ranks which is decidedly tending to disorganise the enthusiasm and higb aims of those who formerly filled the ranks of the profession. There is, in fact, disorder. That this is the outcome of education and general social changes is clear. Bat to stave off this wave of socialism in medicine needs a stronger bulwark than the lean-to wall of your valuable professional journal or any other medical publication of your standard.

Thus, Sir, my fragmentary remarks in THE LANCET in support of "Inspector-General" may possibly only react proportionately as a grain of sand. But medicine is full of hope and, although slow in results, nevertheless a number of grains of sand may affect the whole problem before usviz., the present, nay probably the future, prospects of the medical profession. We are apt to throw stones at glass windows and to blame others for a great deal that befalls the profession when, if we weighed the matter thoughtfully, perhaps we ourselves are sore. There are hundreds of men in the profession striving to aim at good deeds but they are baffled by those whose methods and practice are not pleasant to behold. If we despise the lay advertiser why should this not apply to ourselves, may I ask? Is not personal advertisement contrary to the ethics of the profession of medicine? Why, then, do gentlemen send open postcards and the like through the post seeking patients? Are there no censors in the profession? And, what is worse, how few of us have the courage of their opinions and perhaps are too shy to utter condemnation on personal advertisement? But is not the canker worm of, self-advertisement a sign of stress-an ominous warning for the future of the profession for which some drastic measures will have to be devised sooner or later? It is impossible for a whole body of men to travel along a corduroy road for a length of time without several falling out of the ranks.

Again I will draw attention to another lapse in medicine among the present generation-namely, the using of proprietary drugs and other medicaments foreign to the order of the British Pharmacopoeia. What has become of the good old pill may I ask? And if we do not actually practise empiricism do not we sail very close to the wind and encourage that class of the laity who deal in such things? Altogether, from the drug point of view, are we not getting very muddled?

As concerns our practice, there is no definite ruling as to what constitutes the exact duties of the general practitioner, because his need to earn a living wage encourages him to be Jack of all branches of the profession. Hence arises specialism, but truly there is more dabbling in the specialties of the profession by its members than is justified. And it is questionable whether this dabbling by the recently qualified is not indirectly an explanation of the oft-repeated public censure which the profession as a whole has to endure. In the army we see things are differently managed, for there is a stage of probation, then successive periods, including an examination, before the young man reaches the title of a colonel. And in general civil practice we ought to see something similar, so that a junior should not rank as high as his senior who has practised for many years. The licensing bodies might renew by fresh reception, at varying periods, an extension to practise, gradually weeding out those who by age, incompetency, or irregular practice rightly cease as practising members. Above all, before a candidate qualified to practise leaves the threshold of the licensing body, be it the Royal College of Physicians or the Royal College of Surgeons, there should not be the slightest doubt as to 